\title{
EXPANDING THE PARAMETERS
}

Twenty-five years ago, Nationalities Papers began, ambitiously, though modestly, its mission: to highlight the relatively ignored past and present of the ethnic minorities and nationalities of Eastern Europe and Imperial/Soviet Russia. Many of these minorities were hidden in the shadows of multinational states, where a dominant ethnos and, in Soviet times, anti-particularistic, Marxist-inspired regimes tended to marginalize ethnicity and corresponding cultural aspirations.

Over the years, Nationalities Papers simultaneously both sharpened its focus and broadened the horizons of what are perceived to be ethnic/national minorities and their problems. On the one hand, the journal devoted an entire issue to a people who, until then, were much ignored by the academic community, even by the scholars contributing to Nationalities Papers - the Romani (Gypsies); on the other, it expanded beyond its traditional geographic boundaries by crossing over, for example, into western China's Muslim region, known to its indigenous population as East Turkestan. Over the last ten years, Nationalities Papers has encouraged articles emphasizing the relationship between regionalism and ethnicity. In the same vein, the journal has published articles linking social movements (strikes) to ethnic politics. With each issue a new aspect was added to the complex dynamics of ethnicity, especially in the light of the latter's reemergence in the form of ethnonationalism, now a major political force throughout the world, particularly since the demise of Soviet hegemony.

In this latest issue - a calculated experiment - a constantly modifying editorial policy has initiated the exploration of a still-to-be thoroughly examined topic, namely, the confluence of where women's history and women's contemporary experiences intersect with the powerful demands of ethno-communal values and traditions. The idea to explore the nexus of gender and ethnicity within the covers of Nationalities Papers was somewhat slow in evolving. Few potential authors felt comfortable in an area that called for a dual expertise, and whose methodology was largely still unclear. Fortunately, Professor Barbara Norton (Widener University) was sufficiently intrigued (and brave) to undertake the task of articulating the assignment and persuading authors to tackle the problems posed by the topic.

To her, for all her help, I am deeply grateful. I only regret that her demanding schedule did not permit her to be the sole editor of this pioneering Special Topic issue. She deserves much more recognition than may meet the eye. If the reader finds merit in this issue, much of the credit deservedly goes to her.

On a concluding note, Nationalities Papers wishes to acknowledge, in particular, ChaeRan Y. Freeze's article. It was written in response to the journal's call for 
EDITORIAL NOTE

articles on this topic by senior graduate students. Ms. Freeze's text was selected as the best; we are pleased to congratulate her on her achievement and proud to include her very original piece in this collection.

HRH 